\title{
Dielectrometry Measurements of Effects of Moisture and Anti-Static Additive on Transformer Board
}

\author{
$\begin{array}{lll}\text { Y. Du } & \text { M. Zahn } \quad \text { B.C. Lesieutre }\end{array}$ \\ Department of Electrical Engineering and Computer Science \\ Massachusetts Institute of Technology \\ Cambridge, MA 02139, USA
}

\begin{abstract}
Moisture in solid insulation has detrimental effects on transformer life. When the system is not in equilibrium, laboratory measurements with multiple wavelength interdigital sensors using the imposed frequency-wavenumber $(\omega-\mathrm{k})$ dielectrometry technique have proved to be an effective way to measure complex permittivity distribution in solid insulation which is directly related to the moisture distribution. Measurements of oil-free and oil-impregnated pressboard using interdigital sensors with changes in ambient moisture concentration are presented. A comparison between existing moisture equilibrium curves for the oil-paper system and experimental results is given. Measurements are also performed for anti-static additive in oil and the dielectrometry effects are discussed.
\end{abstract}

\section{Introduction}

The presence of moisture in transformer insulation directly affects the system performance, so it is desirable to monitor its moisture content. For the oil, there are commercial available sensors to measure the moisture directly, and in equilibrium, the moisture content in the pressboard can be obtained using the partitioning curves between paper and oil. However, for solids there is no continuous monitor for moisture under non-equilibrium conditions. The interdigital sensor is able to measure the dielectric properties of liquid and solid insulation by applying the sensor to the surface of the material to be tested. This paper presents results of moisture dynamics of pressboard in air and in oil using dielectrometry measurements. According to the concepts of $\omega-\mathrm{k}$ dielectrometry, application of the spatially periodic potential with wavelength $\lambda=2 \pi k$ and angular frequency $\omega=2 \pi f$ to a surface of a test dielectric generates an electric field which penetrates into the volume of the tested material. Consequently, the conduction and displacement currents which flow into the sensing electrodes depend on the dielectric properties of the sample. The moisture content is then related to the measurable dielectric properties by a calibrated mapping [1].

The improved design of the three-wavelength sensor is shown in Figure 1. Three sets of copper electrodes are deposited on the common Teflon substrate and connected to the interface circuitry.

With $\hat{V}_{D}$ the complex voltage amplitude of the driven electrode and $\hat{V}_{S}$ the complex voltage amplitude of the floating electrode loaded by known capacitance $\mathrm{C}_{\mathrm{L}}$, the complex voltage gain of the sensor is determined by:

$$
\hat{G}=\frac{\hat{V}_{S}}{\hat{V}_{D}}=\frac{G_{12}+j \omega C_{12}}{G_{12}+j \omega C_{12}+j \omega C_{L}},
$$

where conductance $G_{12}$ and capacitance $C_{12}$ reflect material properties.

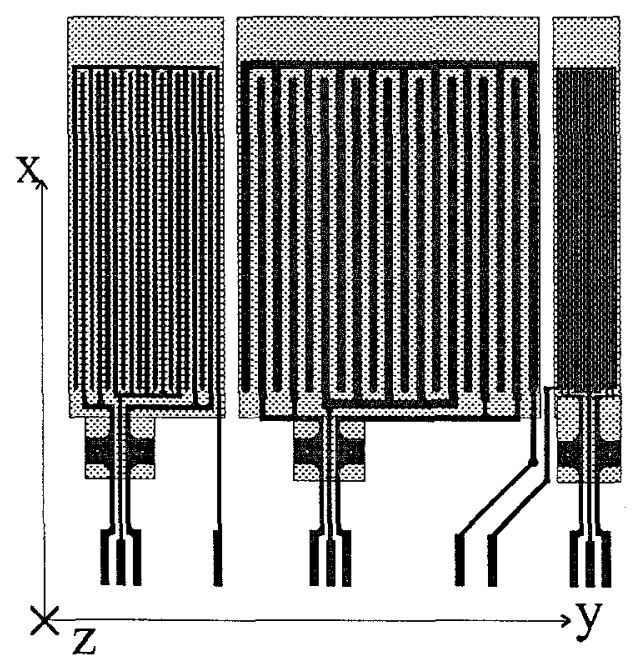

Figure 1. The latest design of the three-wavelength sensor with wavelengths of $2.5,5.0$, and $1.0 \mathrm{~mm} \mathrm{[2].}$

The test facility is shown in Figure 2. The temperature, moisture, and vacuum level of the system can be controlled and monitored. All pressboard samples are made by EHV- Weidmann Industries, Inc. and Shell Diala AX oil is used in our experiments. 


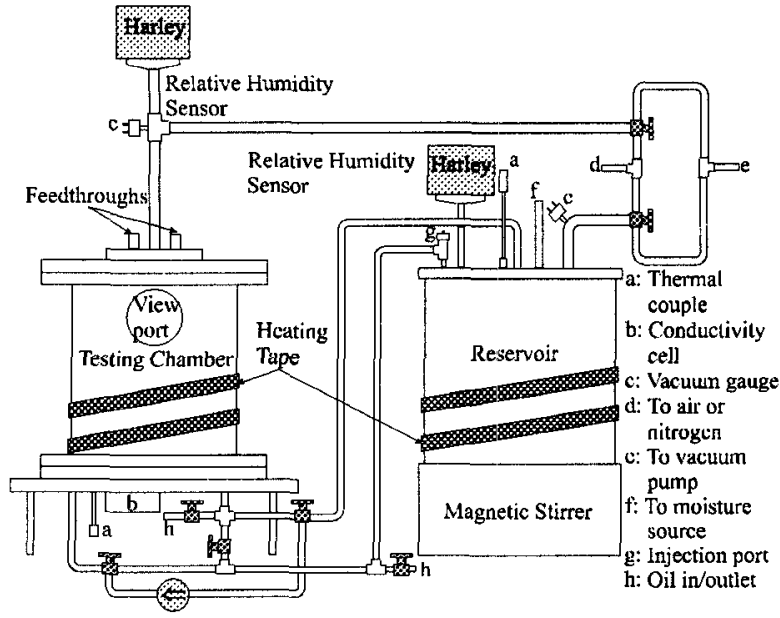

Figure 2. Experimental setup for dielectrometry measurements.

\section{Moisture Measurements}

A three-wavelength sensor is attached to a piece of 3 $\mathrm{mm}$ thick oil-free transformer pressboard in air. Measurements are taken for a frequency sweep from $10000 \mathrm{~Hz}$ to $0.005 \mathrm{~Hz}$. The test sample is brought to 2 torr pressure to observe the drying process of pressboard. As the moisture leaves pressboard under vacuum, the pressboard becomes more insulating. The dynamic process is demonstrated by the frequency shift of the measured gain and phase to lower frequency in Figure 3. Eventually the pressboard behaves as an insulator within the measurement frequency range $\left(\mathrm{G}_{12} \approx 0\right)$, thus the sensing circuitry is a voltage divider between two capacitors $\mathrm{C}_{12}$ and $\mathrm{C}_{\mathrm{L}}$ : constant voltage gain with zero phase shift as given in (1). The responses of the other two wavelengths are similar, but due to different penetration depth, as the moisture diffuses from the outer region of the pressboard, the 5 $\mathrm{mm}$ curves shift to the left in frequency first followed by the $2.5 \mathrm{~mm}$ and then the $1 \mathrm{~mm}$ wavelengths.

In another experiment the reverse process is observed simultaneously using a three-wavelength sensor and a large single-wavelength sensor by introducing wet oil to vacuum dried oil-impregnated pressboard of $1 \mathrm{~mm}$ thickness. The moisture in the oil diffuses into the pressboard and the gain and phase of the sensor measurements change primarily due to the increase in the conductivity.

With different penetration depths, Figure 4 shows that the $5 \mathrm{~mm}$ wavelength changes immediately while the $1 \mathrm{~mm}$ wavelength does not detect the change until almost 30 hours later when the moisture diffuses into the inner region of the pressboard. Results are similar to those in [3] but with a cleaner electrical signal due to system improvements.
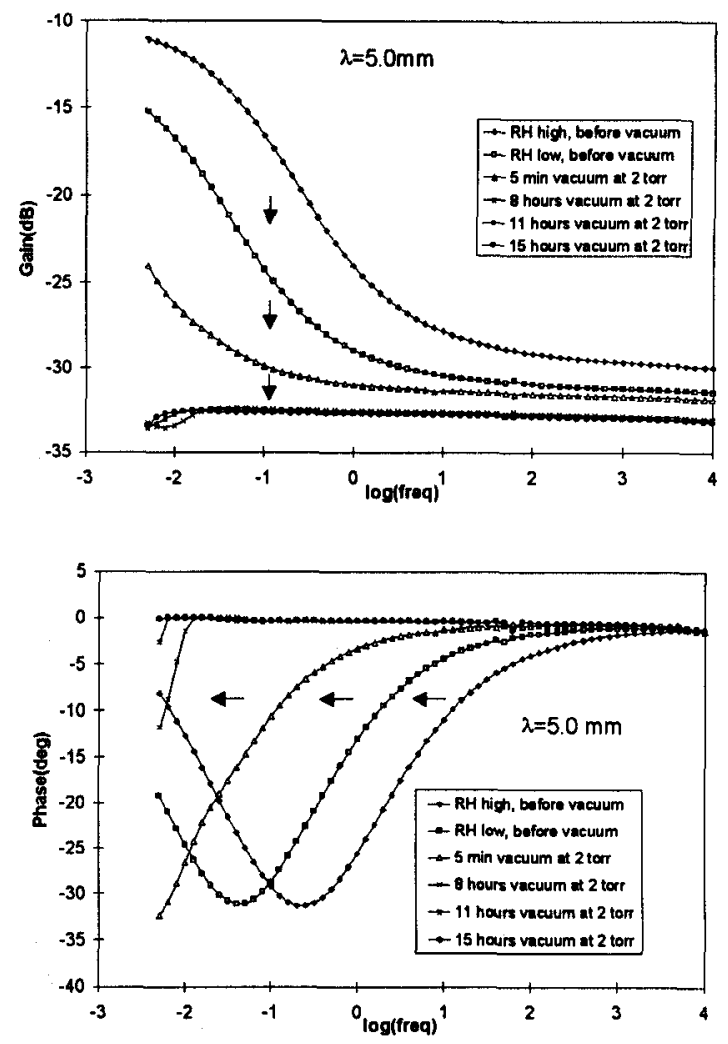

Figure 3. Gain and phase of $5 \mathrm{~mm}$ wavelength sensor measurement for $3 \mathrm{~mm}$ thick oil-free pressboard under vacuum at room temperature.
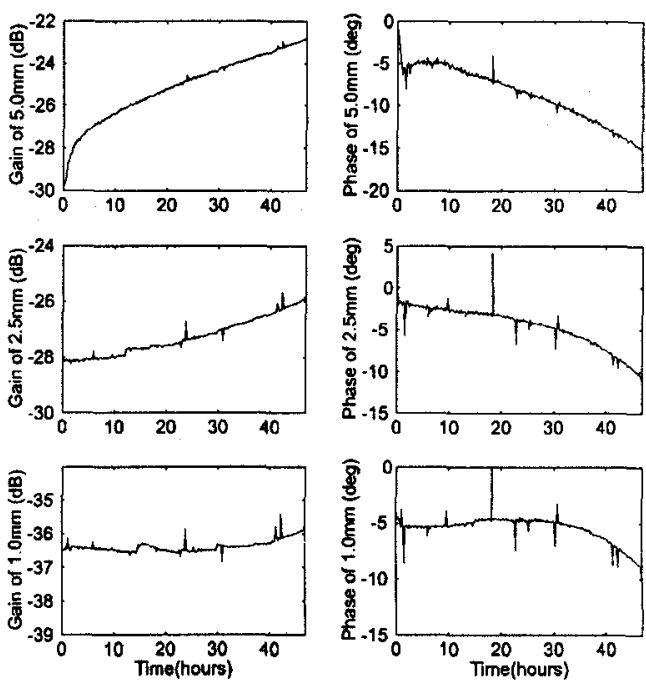

Figure 4. Three-wavelength sensor response for oilimpregnated pressboard at $70^{\circ} \mathrm{C}$ and $f=1 \mathrm{~Hz}$.

The response with the single-wavelength $1 \mathrm{~mm}$ sensor 
is shown in Figure 5. There is a dramatic change after 30 hours. This might correspond to the observations of Rushall in [4] that the loss tangent of the pressboard increases exponentially above $4 \%$ moisture.
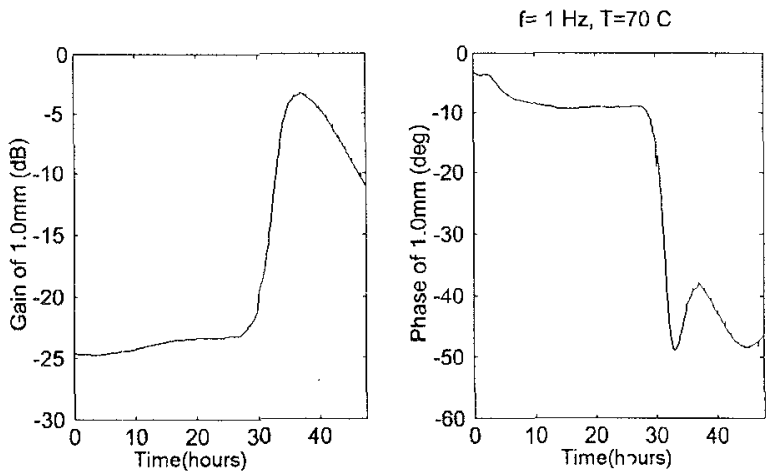

Figure 5. Moisture measurement using $1 \mathrm{~mm}$ singlewavelength sensor.

The final moisture content in the pressboard and oil can be calculated using mass balance either from measurement or predicted by the oil-paper equilibrium moisture curves. An example is given for the moisture data of oil for a similar test.

Method 1: The relative humidity of the oil is measured by the Harley moisture sensor shown in Figure 2 to be about $58 \%$ at the beginning and $32 \%$ in the end equilibrium state. Using the moisture solubility of oil at $70^{\circ} \mathrm{C}$ to be 358 PPM [5], this corresponds to 208 PPM and 115 PPM moisture concentration, respectively. With the total oil mass $5300 \mathrm{~g}$, we calculate that $0.49 \mathrm{~g}$ of moisture diffuses from the oil to the pressboard. This corresponds to a $4.0 \%$ increase of moisture in the pressboard weighing $12 \mathrm{~g}$.

Method 2: Partitioning of water between cellulose and oil has been studied by a number of investigators. A comparison for different curves is shown in Table 1. The difference between the curves is probably due to different materials used to generate the curves or differences in measurement technique.

We could not directly determine how much moisture will be in the pressboard in the equilibrium state for our test from any of the above published curves, since none of them gives moisture concentration in oil greater than $100 \mathrm{PPM}$ while our equilibrium is at 115 PPM. However, by inspection, we find the FabrePichon and Griffin curves won't fit the data, because even at 80 PPM those curves already indicate almost $4 \%$ moisture in paper; the value that corresponds to 115 PPM will be about $6 \%$ by extrapolation and much more than the $4 \%$ estimated in Method 1 . We regenerated the Oommen curves for a wider moisture range as shown in Figure 6 based on the method Oommen proposed in [5] and using the solubility of water data for oil [5] and adsorption curves for wood pulp made from Jeffries' Data [8] by Oommen in Figure 4 of [5]. Since the adsorption curves in [5] all merge near the origin, the region below $1 \%$ Water in Paper in Figure 6 is not very accurate.

Table 1. Comparison of moisture content in paper.

\begin{tabular}{|c|c|c|c|}
\hline Authors & Fabre-Pichon [6] & Oommen [5] & Griffin [7] \\
\hline $30^{\circ} \mathrm{C} 10 \mathrm{PPM}$ & $3.4 \%$ & $3.1 \%$ & $4.0 \%$ \\
\hline $60^{\circ} \mathrm{C} 60 \mathrm{PPM}$ & $4.5 \%$ & $2.9 \%$ & $5.0 \%$ \\
\hline $70^{\circ} \mathrm{C} 80 \mathrm{PPM}$ & $3.8 \%$ & $2.7 \%$ & $3.8 \%$ \\
\hline
\end{tabular}

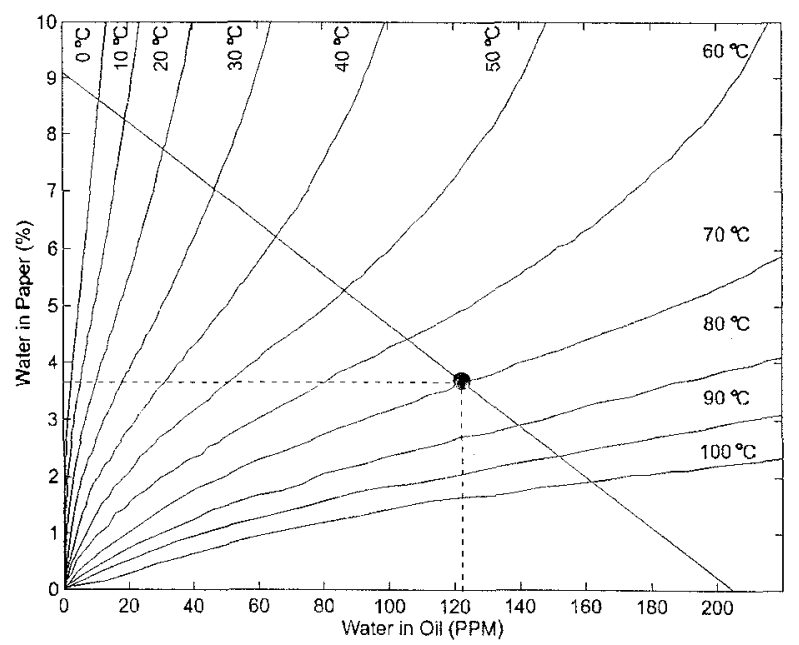

Figure 6. Moisture equilibrium curves for oil and paper system using Oommen's method [5] .

The straight line is the mass conservation curve based on the equation:

$$
P_{\text {paper }} \%=\frac{W_{\text {total }}-W_{\text {oil }}}{M_{\text {paper }}} \times 100,
$$

where $W_{\text {total }}$ (g) is the total moisture mass in the system, which is also the moisture in the oil at the beginning since we start with very dry pressboard; $W_{\text {oil }}$ (g) is the moisture mass in oil during the experiment, which equals the water in oil (PPM) times the total oil mass; $M_{\text {paper }}(\mathrm{g})$ is the mass of the pressboard. $P_{\text {paper }}$ $(\%)$ is the percentage of water in pressboard. Substituting these numbers to (2) gives:

$P_{\text {paper }}(\%)=9.1-0.044 \cdot$ Water in Oil (PPM),

The line is completely defined by the initial condition and the system configuration, i.e. independent of the final moisture measurement. The intersection of the mass conservation line with the moisture partitioning 
curves at $70^{\circ} \mathrm{C}$ indicates the equilibrium value for the system. From this curve, the final moisture in oil is about 122 PPM and the moisture in paper is about $3.7 \%$. This is consistent with the result derived from Method 1.

\section{ASA-3 Measurements}

Anti-static additives are used to increase the conductivity of insulating materials in order to reduce electrification due to liquid flow or high electrostatic charges on the surface. Shell Anti-Static Additive ASA-3 and $1 \mathrm{~mm}$ thick pressboard are used for this investigation.

We inject 0.6 PPM ASA-3 into the oil-pressboard system. It increases the measured conductivity oil at $70^{\circ} \mathrm{C}$ by about 30 times. However, the measurement for oil-impregnated pressboard using either the threewavelength or single-wavelength sensors shows only a very small change in signal.

To further study this, we repeat the process but measure the pressboard complex permittivity using a parallel plate sensor. Sample 1 is enclosed within a parallel plate sensor and the complex permittivity is measured before and after ASA-3 injection to fresh oil. The additive diffuses through the pressboard edges. Sample 2 is thoroughly immersed in the 0.6 PPM ASA-3 oil for three days and is then placed within the parallel plate sensor. Its conductivity is higher than Sample 1 in part due to absorption of moisture. Another 0.6 PPM ASA-3 is injected, and the conductivity of Sample 2 increases very little after 13 hours. The results are shown in Table 2. The change of conductivity of the oil-impregnated pressboard is far less than that of oil.

Table 2. Comparison of the conductivity of pressboard and oil before and after injection of ASA-3.

\begin{tabular}{|l|c|c|}
\hline & Oil $(\mathrm{pS} / \mathrm{m})(1 \mathrm{~Hz})$ & Pressboard $(\mathrm{pS} / \mathrm{m})(1 \mathrm{~Hz})$ \\
\hline $\begin{array}{l}\text { Sample 1, before first } \\
\text { injection }\end{array}$ & 4.5 & 4.3 \\
\hline $\begin{array}{l}\text { Sample 1,17 hours } \\
\text { after first 0.6 PPM }\end{array}$ & 124 & 8.9 \\
\hline $\begin{array}{l}\text { Sample 2, before } \\
\text { second injection }\end{array}$ & 112 & 22.5 \\
\hline $\begin{array}{l}\text { Sample 2,13 hours } \\
\text { after second 0.6 PPM }\end{array}$ & 230 & 23.1 \\
\hline
\end{tabular}

\section{Conclusions}

The multi-wavelength interdigital sensor is able to monitor the moisture diffusion process in pressboard. The experimental results are used to examine existing moisture equilibrium curves for oil-paper system.
Differences are observed between various moisture equilibrium curves.

The ASA-3 additive does not easily diffuse into the pressboard, and thus the dielectric properties of oilimpregnated pressboard do not change significantly. Further study is need.

\section{Acknowledgments}

The authors are grateful for continuing financial support from the Electric Power Research Institute under WO 8031-12, managed by Mr. S. Lindgren, the National Science Foundation under Grant No. ECS9523128, and a Demonstration of Energy-Efficiency Developments Scholarship from American Public Power Association. We would like to thank Dr. T.V. Oommen at ABB-TTI and MIT graduate students D. E. Schlicker and A.V. Mamishev for valuable discussions.

\section{References}

[1] Sheiretov, Y.K. and Zahn, M., "Dielectrometry Measurements of Moisture Dynamics in Oil-Impregnated Pressboard," IEEE Transactions on Dielectric and Electrical Insulation, Vol. 2, June 1995, pp. 329-51.

[2] Mamishev, A.V., Zahn, M., Lesieutre, B.C., and Berdnikov, B.A., "Influence of Geometric Parameters on Characteristics of an Interdigital Dielectrometry Sensor," IEEE Conference on Electrical Insulation and Dielectric Phenomena. San Francisco, USA, October 1996, pp. 550-53.

[3] Du, Y., Zahn, M., Mamishev, A.V., and Schlicker, D.E., "Moisture Dynamic Measurements of Transformer Board Using A Three-Wavelength Dielectrometry Sensor", IEEE International Symposium on Electrical Insulation, Montreal, Quebec, Canada, June 1996, pp. 53-56.

[4] Rushall, R.T., "Dielectric Properties of Oil-Soaked Pressboard as Affected by Water," Proceedings of The Institution of Electrical Engineers, Part IIA, vol. 100, No. 3 , March 1953, pp. 81-88

[5] Oommen, T.V., "Moisture Equilibrium in Paper-Oil Systems", Proceedings of the Electrical/Electronics Insulation Conference, Chicago, II, October, 1983, pp. 162-66.

[6] Fabre, J. and Pichon, A., "Deteriorating Processes and Products of Paper in Oil. Application to Transformers". 1960 International Conference on Large High Voltage Electric System (CIGRE), Paris, France, Paper 137.

[7] Griffin, P.J., et al. "Comparison of Water Equilibrium in Silicone and Mineral Oil Transformers," Minutes of the Fifty-Fifth Annual International Conference of Doble Clients, 1988, Sec. 10-9.1.

[8] Jeffries, R., "The Sorption of Water by Cellulose and Eight Other Textile Polymers," Joumal of the Textile Institute Transactions, Vol. 51, No. 9, 1960, pp. 339-74. 